\title{
The path from business modelling to technology management
}

\author{
Stefan Bleck, Tomaso Forzi, Peter Laing and Volker Stich \\ Research Institute for Operations Management (FIR), Aachen University of Technology \\ (RWTH Aachen),E-Business Engineering Department, Pontdriesch 14/16, 52062 Aachen, \\ Germany \\ Email: $\{b l$, fol, la, st $\} @ f i r . r w t h-a a c h e n . d e$
}

\begin{abstract}
Nowadays, the Internet and web-based E-Business solutions play a crucial enabling role for the design and implementation of new Business Models. This implies high chances, but also remarkable risks for enterprises that choose to pursue a new Business Model striving to exploit new technology potentials. In fact, the implementation of a strategically not appropriate Business Model or the definition of an inconsistent technology portfolio would critically undermine the long-term success of a company. Hence there is a clear need for action in the field of methodical Business Modelling. We present a new approach for a customer-oriented E-Business Modelling, with specific attention on inter-organisational cooperative networks and re-intermediation, as well as on technology management within distributed manufacturing networks. The approach had been validated within the design process of an information service intermediary, whose objective is the support of a collaboration network in the German manufacturing industry.
\end{abstract}

Keywords

E-Business Engineering, Business Modelling, Technology Management, Information Service Intermediary, Collaborative Networks, and Distributed Manufacturing Systems.

\section{INTRODUCTION}

During the past years, the fast development of new Information and Communication Technologies (ICTs) has been revolutionizing the market arena and it extended the horizon of competition (Hagel \& Singer 1999). Such development has been causing radical changes in all business branches (Afuah \& Tucci 2001, Bensaou 1997, Gebauer \& Buxmann 1999, Hagel \& Singer 1999, Holland \& Lockett 1994, Kornelius 1999, Picot et al. 2001, Porter 2001, Rentmeister \& Klein 2001, Shoder 2000, Timmers 2000, Wirtz 2000). New ICTs and the related new business approaches allow enterprises to design leaner intra-organisational processes, with the result of enhancing efficiency and productivity (Mooney 1996, Pietsch 1999, Ruohonen 1996, Teubner 1999). Besides that, ICTs can strongly influence inter-organisational processes, by supporting cooperation within 
entrepreneurial networks as well as by enabling their coordination - by means of Internet-based Business Collaboration Infrastructures (BCIs), such as Electronic Marketplaces, Exchange and Communication Platforms or Supply Chain Integrators (Klein 1995) (Hoeck \& Bleck 2001) (Schoder 2000). Hence, web-based ICT solutions play a crucial enabling role both for new Business Models and for those models that, until now, had a higher value on a theoretical than on a practical level (e.g. Virtual Organizations) (Forzi \& Luczak 2002, Picot et al. 2001). Anyhow, a lot of open issues and unsolved problems in the field of technology fulfilment are still to be faced in order to ease an efficient entrepreneurial collaboration within globally dispersed networks, as e.g. the definition of suitable branch-specific standards for inter-organisational business processes (Gebauer \& Buxmann 1999, Krcmar 2000, Teubner 1999).

As far as inter-organisational processes are concerned, recent trends show that companies, in order to face the quick-paced globalisation process, tend to concentrate on their own core competencies, before starting to cooperate within global networks of enterprises (Hagel \& Singer 1999, Kornelius 1999, Molina et al. 1998, Parolini 1999). This transformation process is crucial for the success of the company's business (Picot et al. 2001). Therefore, before making a strategic decision regarding the participation to a cooperation network, the management of an enterprise has to take into consideration a wide set of aspects, such as the entrepreneurial organization, the own core competencies, the needs of the customers, the readiness of the potential partners to cooperate, and the availability of the needed technologies and tools (Bleck et al. 2001, Forzi \& Luczak 2002, Hagel \& Singer 1999, Porter 2001, Timmers 2000).

In particular, enterprises have to weigh a set of crucial success factors in the fields of standardization and information technology management (Gebauer \& Buxmann 1999, Krcmar 2000). For instance, on the one side communication standards are essential to achieve an efficient exchange of information and data (Bergner et al. 2000). On the other side, branch-specific collaboration standards are crucial to establish inter-organisational workflows (Holland \& Lockett 1994). Furthermore, the analysis of the potentials of new technologies can help to select the most suitable technologies and tools for the support of new entrepreneurial businesses (Bleck \& Quadt 2002) (Schoder 2000). A proper technology and innovation management is important to plan the development of the entrepreneurial core businesses in coordination with a strategic technology planning (Bullinger 1994, Hoeck \& Bleck 2001).

As a result, in order to deploy innovative network-oriented cooperation structures, new (Internet-based) Business Models can be designed and successfully implemented (Afuah \& Tucci 2001, Rayport 1999). Amongst other aspects, the processes of intermediation and disintermediation are relevant phenomena in this context (Rose 1998, Klein 1995, Ruohonen 1996, Schoder 2000).

In order to meet this challenge, we present a new business modelling approach validated within the design process of an information service intermediary to support a distributed manufacturing network; hence, we focus on the design of information models in a networked economy. Thus, in order to identify the needed ICTs for a new E-Business Model, we outline a new planning methodology to incorporate the interdependencies between inter-organisational processes and ICTs. Thus, we 
present a case study to ease the understanding of our research. Eventually we draw a set of conclusive considerations and highlight the further need for action.

\section{STRATEGY AND CUSTOMER-ORIENTED BUSINESS MODELLING}

\section{Entrepreneurial Strategy and the Internet: New Business Models}

In the management literature there are different and discrepant definitions of the concept of Business Model (Afuah \& Tucci 2001, Timmers 2000, Wirtz 2000). Furthermore, (E)-Business Models can be classified according to the most different criteria, such as the degree of innovation and functional integration, the collaboration focus or the involved actors (Rentmeister \& Klein 2001, Timmers 2000, Wirtz 2000).

The core objective of each company is a long-term creation of added value (Porter 2001). The entrepreneurial strategy defines how such a target has to be fulfilled. A successful strategic positioning is achieved through a sustained profitability, an own value proposition, a distinctive value chain, an entrepreneurial fit, and continuity of strategic direction (Porter 2001).

According to our understanding, a Business Model is an instantiation of an entrepreneurial strategy related to a specific business and it encompasses six different sub-models (see Figure 1): (1) Market model: definition of the market(s) of action (targeted customers as well as potential competitors); (2) Output model: definition of the output requirements and design of the outputs (products or services); (3) Revenue model: estimation and calculation of the expected revenues; (4) Production design: design of how the performances have to be deployed; (5) Network and information model: partner selection and configuration of the network, as well as configuration and management of the (distributed) information; and (6) Financing model: scenario-based definition of risks and expected profits to search for investors or to persuade the stock holders.
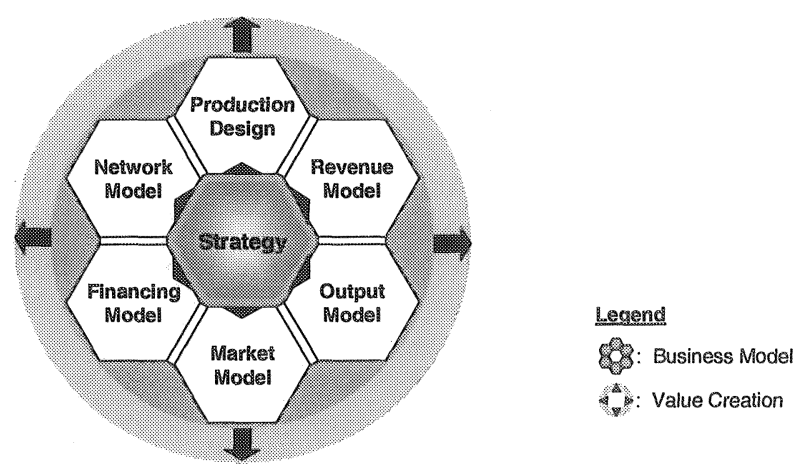

Figure 1 - Strategy, Business Model and creation of Added Value 
In the new ICT era, companies strive to exploit the advantages of the networked economy. Lately, Business Models tend to involve different enterprises with the goal of bringing higher profits to each of the participants (Afuah \& Tucci 2001, Picot et al. 2001). The modelling of such cooperative E-Business Models represents a significant challenge, since there are no appropriate methods to tackle systematically such modelling issue. We developed a customer-oriented business modelling approach for intermediaries within dispersed manufacturing networks.

\section{The House of Value Creation}

Due to the globalisation, the growing transparency of the markets and the resulting increased competition, enterprises have to focus more and more on their customers. As a matter of fact, the fulfilment of the customers' needs is an essential precondition to generate turnover. This means that enterprises have to take this aspect into deep consideration and must consequently shape Business Models that reflect the customers' needs (Forzi \& Laing 2002).

Because of the above mentioned reasons, until now the development and adjustment of Business Models has been performed by companies mostly in a creative way. As a matter of fact, in the state-of-the-art there is hardly any holistic methodical support. We are convinced that a successful approach to tackle this methodical lack must be based on a strategic focus on the customer's needs. Within a running research project, we developed the House of Value Creation (HVC), a method to design customer-oriented and sustainable Business Models (see Figure 2) (Laing \& Forzi 2001). The HVC is a meta-method, since it consists of three logical pillars (input, method, and output) and of six process layers (each of the process steps requires a suitable method). The method suits explicitly the design of Internetbased Business Collaboration Infrastructures (Forzi \& Laing 2002).

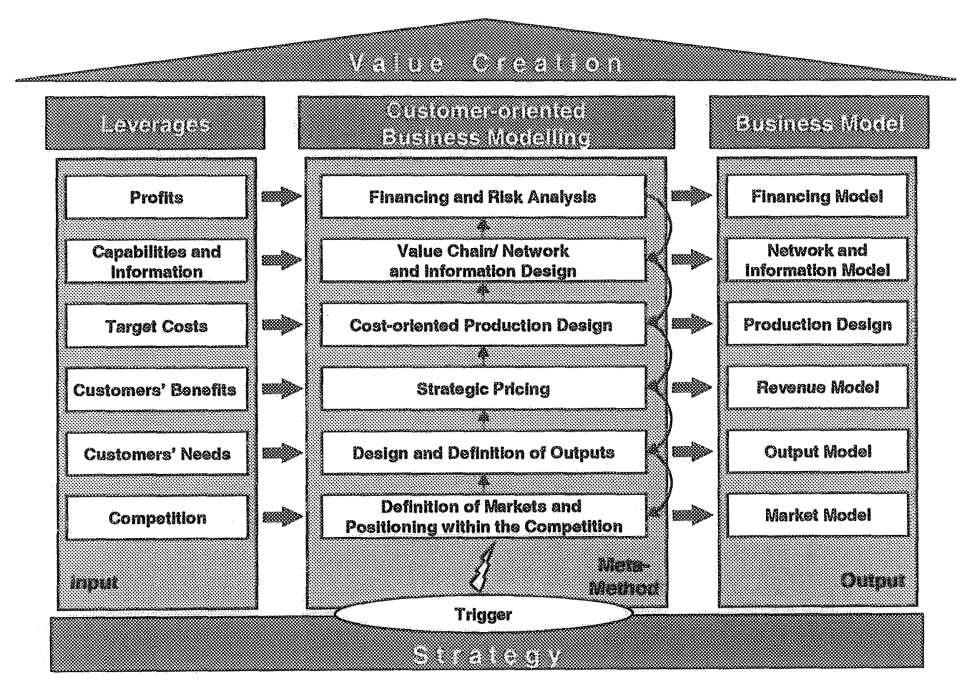

Figure 2 - The House of Value Creation 
Because of our understanding of the term Business Model and because of the fact that the ultimate goal of a company is long-term value creation, the design of a Business Model has to be definitely based upon the entrepreneurial strategy. Therefore, if not already done, the first step within a business modelling process is to define the rough entrepreneurial strategy, on which the Business Model will be based (Laing \& Forzi 2002b). The meta-method of the House of Value Creation illustrates the correlation between a set of significant leverages (first pillar of the HVC), the Customer-oriented Business Modelling process (second pillar), and the resulting Business Model (third pillar). As previously hinted, our Business Modelling approach encompasses six layers that correspond to six following steps of the method. The first HVC phase is triggered either by the inside or by the outside of the company - through a new idea, invention, innovation or modifications of the economical environment. The six steps of the method are (Laing \& Forzi 2001):

1. Definition of the markets and positioning within the competition. The initial decision regards the category of products or services to deal with (as well as the substitutes). Hence, a consequent monitoring of all strong players (suppliers, customers, and possible competitors) has to be done. This phase deals with the branch profitability and with the rivalry among existing and potential competitors. Phase output: market model, with a clear identification of the key players, customers and competitors.

2. Definition and design of the outputs. In the product design, a well-proven method is the Quality Function Deployment (QFD) (Pfeiffer 1993, Warnecke et al. 1995, Hoffmann 1997). With this approach, a customer-oriented product development can be successfully realized. Therefore, after defining markets and identifying core customers and competitors, the outputs (physical products or services) have to be shaped in order to maximize the customers' benefit according to a QFD-like method. Phase output: output model, with a detailed customer-oriented design of the outputs.

3. Strategic pricing. The identification of prices for the planned outputs should be more the result of a strategic positioning than of a cost-oriented approach (Forzi \& Laing 2002, Hagel \& Singer 1999). The price calculation should take into consideration the customers' surplus constraint as well as the strength of the competition-existing barriers of entry, such as patents, industry property rights, etc. (Kim \& Mauborgne 2000). Phase output: revenue model, with a detailed description of how earnings will be achieved.

4. Cost-oriented production design. According to the guidelines of the revenue model, the target costs for the output model will be calculated (as the upper bound for direct costs). Hence, the requirements to the value chain will be detailed. Phase output: production design, with a detailed description of how the performances have to be achieved.

5. Partmers, network and information. In this phase, starting from the requirements on performances of the value chain, the capabilities (core competencies, capacities, available modules and components, ICT infrastructure) of the own performance structure and of the potential partners will be thoroughly scanned. Phase output: network model, selection of the partners within a specific instantiation of the value chain and network configuration, as well as information 
model, i.e. the approach according to which the information management issue has to be tackled.

6. Financing and risk analysis. Eventually, based upon the expected profits and a suitable scenario analysis, the risk-level as well as the need for working capital must be calculated to start the search for investors (Fink et al. 2000). Phase output: financing model.

At each step of the HVC the corresponding targets must be fulfilled. If one step is not fulfilled, then the process should go back to a prior phase as long as the issue is tackled - with an iterative approach.

In the following section, our contribution will focus on a specific level of our HVC, namely the one regarding network and information model. A specific attention will be paid to the necessity to manage information, information flows and ICTs within distributed manufacturing networks and to the approach with which such goal set can be achieved.

\section{The Design of Information Models in a Networked Economy}

In the $5^{\text {th }}$ phase of the HVC customer-oriented Business Modelling, starting from the requirements on performances of the value chain, the state-of-the-art and the capabilities of the own performance, information structures and ICTs, as well as of the ones of the potential partners, will be thoroughly scanned. The striven value chain will be designed and a specific network will be instantiated.

As stated in the initial section, before making a strategic decision regarding the creation of a cooperation network, the management of an enterprise has to take into consideration a wide set of aspects, such as the entrepreneurial organization, the own core competencies and the ones of the partners, and the available technology. The gathering of all information regarding the potential network participants represents what we define as capabilities and information. According to the requirements previously identified within the production design (output of phase 4 of the HVC), a crosscheck with the capabilities of all potential partners helps to define the set of suitable partners. This process can be supported e.g. by the use of specific intermediaries such as vertical E-Marketplaces. The data about the entrepreneurial capabilities must regard both the own performances, the ICT capabilities as well as the maturity of the involved technologies (Krcmar 2000, Picot et al. 2001). As a result, the instantiation of a specific network configuration can be identified. Furthermore, the definition of inter-organisational blue prints and branch-specific process standards is necessary to enable lean and efficient inter-organisational processes and workflows.

The result is the network model (see Figure 3) (Laing \& Forzi 2002b). The most relevant aspect for the following phase is that the inter-organisational processes determine the sources and the sinks of distributed information. The information design focuses on the management of the information within such entrepreneurial networks and inter-organisational value chains (see Figure 3). Within the modelling of an inter-organisational information management model, we distinguish three different layers (Laing \& Forzi 2002a): 


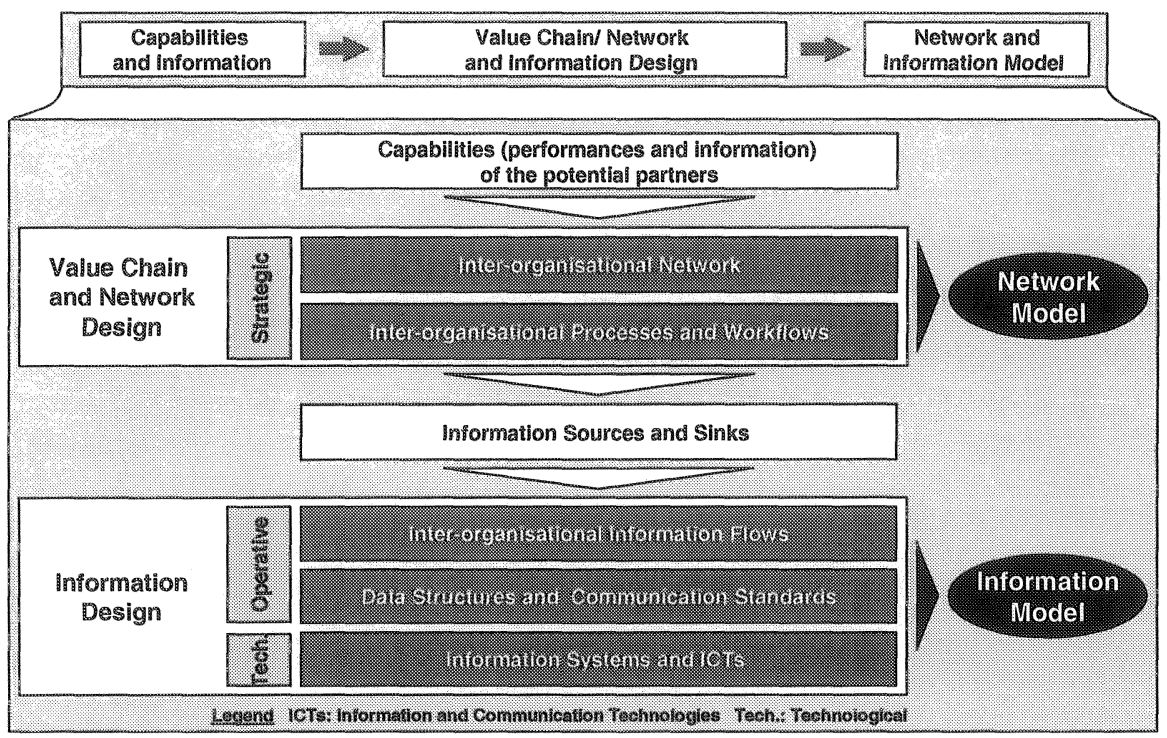

Figure 3 - Interorganisational Network and Information Models

1. Inter-orgamisational Information Flows. Starting from the sources and the sinks of distributed information, the inter-organisational information flows can be derived and consequently defined. Within this process, several different aspects have to be taken into consideration: direction (e.g. one way or bi-directional information flow), involved actors (broker, network members, and related intelligent agents), involved systems (e.g. knowledge management, distributed Data Base information sources), and relationship (e.g. 1: 1, 1: n, m: n). Furthermore, information flows encompass two other major dimensions: information width, which sets the different degrees of information broadcasting and transparency within the network, and information depth, which defines the scope, aggregation level and content of the information flow.

2. Inter-organisational Data Structures, Communication Standards. A crucial issue is the development of an inter-organisational data model to ensure the consistency, quality and transparency of the data. A data model encompasses also the aggregation levels for Management Support Systems (e.g. Data Warehousing and Data Mining). Furthermore, the branch-specific development of shared communication standards (e.g. based on XML) is essential to achieve and ensure a fast exchange of information and data through inter-organisational networks, as well as the integration of different ERP systems within an Internet-based BCI. The identification of the most appropriate technology standards is also important to deploy a back-end integration in each of the involved enterprises. Eventually, an appropriate solution for the security issue has to be identified.

3. Information Systems and ICTs. Enterprises have to weigh a set of crucial success factors in the field of technology management. The analysis of the potentials of new technologies as well as their diffusion and maturity can help enterprises to select the most suitable technologies to face challenges in the context of new collaborative businesses. For instance, the technical support of information flows in 
relation of complexity of the considered job and of the media richness (regarding e.g. real-time or asynchronous response) can be done according to the Media Richness Theory (Daft \& Lengel 1984). As a matter of fact, a proper technology and innovation management is important to plan the development of the entrepreneurial core businesses in coordination with a strategic technology planning (Bleck \& Quadt 2002, Bullinger 1994, Krcmar, 2000). Last but not least, a make or buy decision has to be taken, e.g. between the exploitation of the services of an Application Service Provider and the development of an own platform.

Within the definition of Information Systems and ICTs, one of the most crucial issues is the identification of the most appropriate ICTs out of the set of all suitable technologies that might suit to the striven target (Bensaou 1997, Bleck \& Quadt 2002, Bullinger 1994, Daft \& Lengel 1984, Gebauer \& Buxmann 1999, Krcmar 2000, Mooney 1996, Pietsch 1999, Teubner 1999). Because of the dynamic technology development, the temporal horizon has to be considered in detail within the network and information modelling phase. As a matter of fact, the development of innovative ICT-based solutions requires an appropriate consideration of both available and future technology potentials. Furthermore, the future technology potentials usually imply an impact on the network organisational structure. This means that interdependencies between the network model and the information model have to be taken into consideration, when carrying out a middle or long term analysis. In order to meet this peculiar challenge, in the next section we outline a new planning methodology that incorporates the interdependencies between network structure and processes on the one hand and ICTs on the other hand.

\section{INTEGRATED PLANNING OF ORGANISATIONAL STRUCTURES AND TECHNOLOGY}

In order to fully benefit from the advantages of the inter-organisational cooperation, the network needs a sustainable support of Information Systems and ICTs. As pointed out above, the adequate identification, selection and management of suitable Information Systems and ICTs is a great challenge. In fact, there might be many different, often even partly competing network partners, whose different needs (also over the time) must be considered when selecting and assessing ICTs and electronic services to support the network (Bensaou 1997, Bleck \& Quadt 2002, Gebauer \& Buxmann 1999, Rose 1998, Schoder 2000). Within our research, we observed that various ICTs are capable to support the different inter-organisational processes and workflows. In order to guarantee smooth inter-organisational processes, the selected ICTs must therefore be integrated seamlessly. Furthermore, the high pace of technical development requires a planning process that considers both currently available and also future ICT-solutions (Bleck \& Quadt 2002, Bullinger 1994, Krcmar 2000, Teubner 1999). Finally, the potentials of future ICTs might influence the network structure, so that the business relations between participating companies may also change over the time (Gebauer \& Buxmann 1999 , Rose 1998, Ruohonen 1996, Schoder 2000). Therefore, potential impacts on the network must be considered and evaluated when selecting and assessing specific Information Systems and ICTs as network infrastructure. This is what we define as 
Integrated Planning and Management of Networks and of Information Technology. Figure 5 shows how the temporal interdependencies of network structure and processes and ICTs should be integrated into the planning process. This enables the decision-makers to assess the mutual influences and hence to deploy appropriate measures. We will now present an approach with which such a result can be achieved.

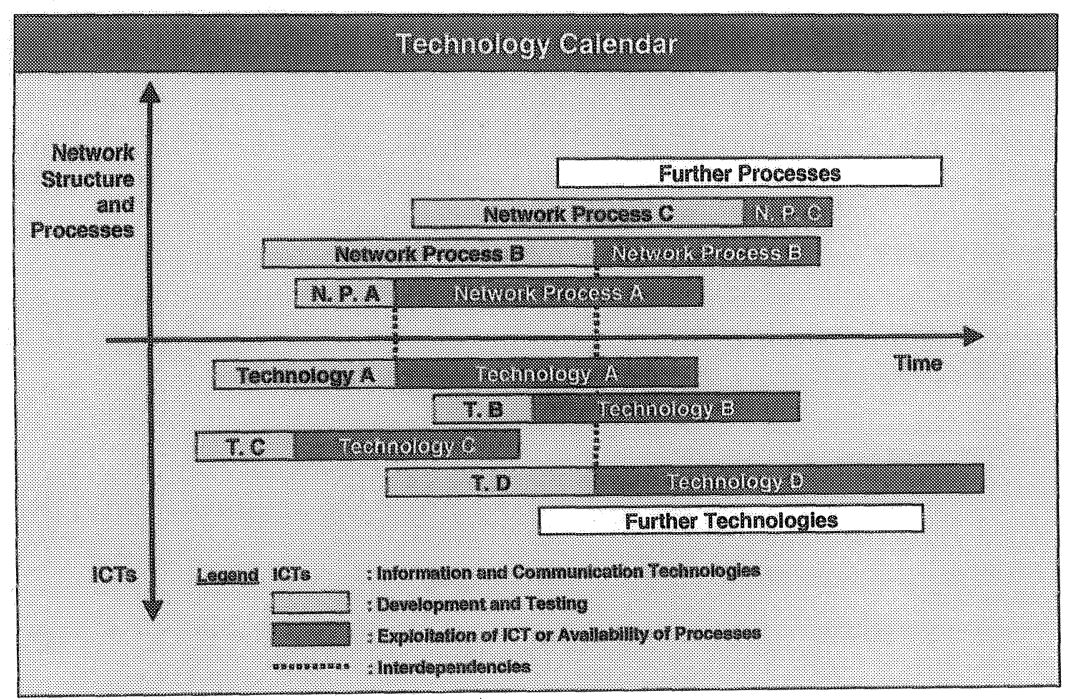

Figure 4 - Integrated Planning of Network and ICTs

First of all, because of the complexity related to this planning task, a suitable description model is fundamental for a successful planning. As a matter of fact, such a model must describe all characteristics of potential networks, the different parameters of ICTs as well as the complex links between these two clusters. As previously stated, this approach has to enable the full and sustainable exploitation of technologies over the time and herewith the implementation of new and unique network structures.

For this reason we developed an integrated description model to identify and highlight the interdependencies between different network instantiations and the underlying technologies (see also Davenport 1993). Our model (see Figure 5) fulfils the above-mentioned requirements. 


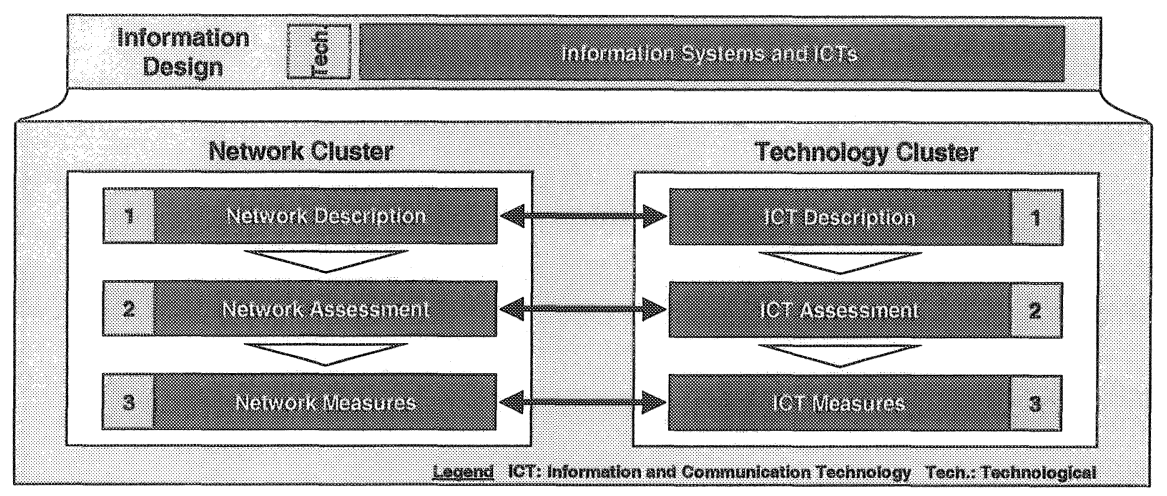

Figure 5-Integrated Description Model for Planning of Information Systems and ICTs

The description model consists of three layers for each of the two clusters. These layers correspond to three different steps within the planning and management process. The first layer is a crucial step within the model and it aims at the description of networks and ICTs as well as their matching. In Figure 5, the matching is represented by the arrows. In the second layer all relevant factors for the assessment of the feasibility as well as the sustainable cost-effectiveness are collected and compared. Eventually, in the third layer the necessary measures to deploy a specific network as well as to develop and exploit the appropriate ICTinfrastructure are derived. Within the last two steps a particular attention is paid to temporal constraints, as illustrated in Figure 4.

As mentioned above, the description and matching of the network and ICTs in the first layer is a complex task, because of the existence of several interdependencies between the two clusters. In order to enable an easier matching it is helpful to distinguish between network processes and organisational potentials on the one side as well as ICT functionalities and ICT potentials on the other side (see Figure 6).

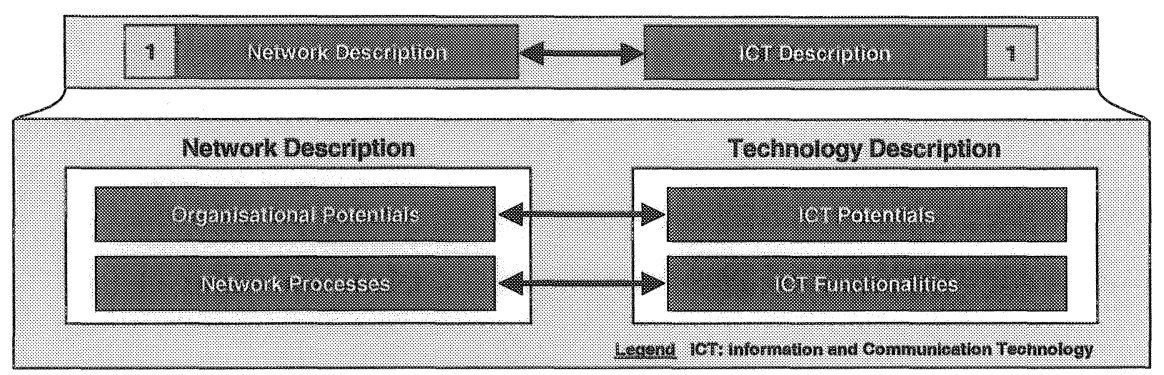

Figure 6 - First Layer of the Integrated Description Model

According to our understanding the organisational potentials represent the capability to develop and implement innovative organisational concepts (in this specific case regarding the network structure). Clearly this requires a creative process that has to take into consideration the potentials of existing and planned ICTs. Examples for organisational potentials are for instance the ability to work in 
distributed environments without suffering the disadvantages caused by the lack of e.g. face-to-face communication. Furthermore, examples of ICT potentials are the overcoming of temporal and spatial barriers through the use of the web-based technologies.

The network processes are the specific instantiation of the inter-organisational processes and workflows, as we previously defined within the value chain and network design of the network model (see Figure 3). These processes need to be supported by ICTs. The ICTs can be further described by their functionalities, which specify which task the particular technology can perform. According to our understanding, the functions have to be elementary, this meaning that each technology can be associated with exactly one function (see also Ropohl 1999). As a matter of fact, we identified four clusters of elementary functions, and namely:

- Input and Output functions. These functions, often also called User Interface, include especially audio and video technologies. The decision about the input and output technology that is the most appropriate to support the network partners and customers depends heavily on the information that needs to be presented.

a Processing fumctions. Processing technologies allow the modification and analysis of input data to generate the needed information. The necessary processing capacity for a certain task is a relevant criterion in this context, and operating systems and programming languages must also be taken into account.

- Transmission functions. Since the cooperating enterprises are often widely distributed, communication technologies and standards are needed to transmit information between technical devices and/or network partners.

- Storage functions. Clearly, before and after any handling and modification of information, the corresponding data must be stored.

Although all these functionalities are not completely independent, hardware and software technologies can be identified in each cluster; hence, each cluster can be to some extent dealt with separately. The functions are described in detail by a set of parameters. Furthermore, the parameter set depends on the particular function and technology. Storage technologies, for instance, are characterised by capacity and access time, while transmission technologies are classified according to e.g. bandwidth, bit error rate and jitter.

After the network processes have been defined, each specific network process step has to be matched with all suitable technologies that might support it. For example, the requirements related to the exchange of information and data between different network partners need to be matched with all available technologies that enable transmission functions, e.g. transmission protocols, standards or light-wave cables. As a result, the technology or set of technologies with the most suitable parameters is selected.

According to our understanding, the above-mentioned method is a successful approach to deal with the challenge to match value chain and network design with the management of technology within the information design process. In the next section we will show, with the help of a case study, how the potentials of our method can be exploited. 


\section{A CASE STUDY - Development of an $\mathbb{E}$-Business Collaboration Infrastructure for an Information Service Intermediary}

Each industrial sector has its own peculiarities; therefore, it is necessary to develop approaches and solutions that take into account such specific requirements. Our institution has a proved experience with German SMEs of the manufacturing and machinery industry. Since we identified a remarkable need for "e-action" in this traditional and static industrial branch, we therefore decided to develop customized Business Models and E-Business solutions with a high impact onto this industrial sector. In this context we developed the case study for the present contribution.

The case study has been conducted in the field of manufacturing networks for metallic material with 10 German SMEs. As a matter of fact, the generation and mailing of so-called paper-based test reports for metallic material, which documents and guarantees to the buyer specific material properties, is nowadays accompanied by several serious problems. For instance, the open issues concern the archiving of reports, the specification check of corresponding material standards or norms referenced in a test report (DIN 1990).

The innovative trigger for this case study is the worldwide dissemination and acceptance of the Internet as communication and information exchange channel as well as the idea to exchange material test reports electronically. This makes the development of new intermediary services for the efficient exchange and storage of material test reports based on an electronic Business Collaboration Infrastructure feasible. Based upon the innovative idea of exchanging electronic material reports on a collaborative Internet-platform, we proposed a Business Model - the result of the use of the House of Value Creation. We are now going to present the results obtained within the business modelling process.

\section{Market model}

After a thorough market analysis we identified similar solutions to manage and exchange material reports (e.g. Document Management Systems, DMS), but we realized that none of them fulfils all relevant requirements. Hence, in the resulting market model there are no direct competitors because of the fact that the planned service is innovative and therefore it is not offered in the market yet. Furthermore, the potential customers are all the manufacturing enterprises that exchange metallic products - i.e. both ferrous metals (all sorts of steel) and non-ferrous metals (such as tin, copper, and brass) - with specified and guaranteed properties, as well the different testing and inspection organizations (such as TÜV or Dekra in Germany, Det Norske Veritas in Norway, BSI or ITS in Great Britain, SGS in Switzlerland, Bureau Veritas in France).

\section{Output model}

We conducted several workshops with the involved SMEs and thus we gathered all the requirements related to the exchange of electronic material test reports in the manufacturing field. We distinguish two kinds of groups of services required by the potential customers of the platform: 
- Basic service, e.g. storage, access, and remote archiving of electronic material test reports over the Internet.

- Value-added services, e.g. assessment and evaluation of the suppliers, nominal/actual value comparison of measures certified in a test report, batch management, offering of detailed information about material-related quality.

Other general requirements on the overall performances of the platform are: a high operating efficiency and flexibility, specific security requirements (e.g. transmission and privacy), a $24 \times 7$ hours system availability, a suitable multi user concept with different and adjustable levels of authorizations, support of surveyors of independent testing and inspection organizations.

\section{Revenue model}

After an analysis of the customers' benefit, we used a two-step price corridor method for the strategic pricing for shaping a revenue model (Forzi \& Laing 2002):

\section{Identification of the price corridor of the mass}

The search for the price corridor that the majority of the customers are willing to bear. According to the market model, there are no direct competitors, but only some possible substitutes, i.e. providers of DMS, whose products, though, do not fulfil all relevant customers' requirements. We observed that the innovative services of the planned intermediary service infrastructure might therefore crucially change the power balance in the market of tools for the management and exchange of material test reports. The current cost to process a single material report amounts up to about $50 €$, which clearly represents an upper bound for the price model. Since the process cost for an electronic test report drops drastically by the use of the intermediary service infrastructure, the decision was to pursue a low price corridor strategy to target a high number of customers.

\section{Specification of a level within the price corridor}

Identification of an appropriate price level within the chosen low price corridor. A detailed analysis of the customers' benefit of the DMS underlined that none of them can fulfil all industrial requirements. Therefore, the intermediary service infrastructure with its innovative customer-oriented services has realistic chances to be widely accepted by the target group and thus to penetrate successfully the market. In order to conquer the market and achieve the striven critical mass in terms of traffic (reports/period of time), it was furthermore decided to choose a lower pricinglevel within the chosen low price corridor. A high traffic, though, does not yet guarantee a long-term success, because second-movers might come up with similar solutions and gain quickly market share. Hence, the price should be maintained very low until the critical mass in terms of branch members is also reached. With the achievement of this goal, the developed format for electronic test reports will be widely disseminated and it has therefore good chances to be accepted and adopted as a branch-specific standard. At this stage, barriers for market entry for possible competitors will be significant. The deployment of a mid or upper-level pricing 
within the selected price corridor will be then possible without risking to loose market shares. A potential cash cow for the business is represented by the portfolio of attractive value-added services.

\section{Production design}

According to the guidelines of the revenue model, the target costs for the output model will be calculated within the cost-oriented production design, i.e. design of the electronic transmission, management and storage of material reports. In the case of the "production" design for the transmission of material reports, the attention was paid to the fixed costs (i.e. target costs for the infrastructure) since direct costs (i.e. cost for the report transmission) tend to zero. Hence, the result is a platform with a targeted low fixed cost (e.g. hardware, software and mainly personnel costs). The lower the fixed costs are, the sooner the critical mass in terms of participants and transactions will be reached.

As far as concerns the design of the platform, we identified the need for the following capabilities: database based material test reports management and archiving, material science know how, trust management, and information content for value-added services.

\section{Network and information model}

In this phase, starting from the requirements on performances and from the capabilities, core competencies and IT infrastructure of the involved potential partners, a specific performance network as well as an information and technology framework were defined.

The targeted market consists of several SMEs, of which none of them is dominating the market. It is important that all enterprises that take part to the platform must trust and be able to rely on the carrier. Hence, the managing institution of the transaction platform for electronic test reports must be an independent company. It was thus decided that the collaboration platform should not be managed by one of the manufacturers of metallic material, but by a neutral intermediary with material science know-how as well as ICT competence (e.g. data base management and archiving). As a matter of fact, the archive management and value-added services that require particular material science know-how will be performed by the intermediary, who will outsource the other competencies to two different partners; one partner was identified to deal with trust management and another to provide information content for the other value-added services.

Within the analysis of the information infrastructure, the crucial issue was the modelling of processes and the management of shared information to enable the inter-organisational and intra-organisational workflow capabilities of the planned ICT-System. Furthermore, some of the other most interesting aspects that were dealt with are the definition of process standards for inter-organisational processes and workflows, the development of an appropriate and flexible interface to deploy a back-end integration in each of the involved enterprises, and the branch-specific development of a shared standard for electronic test reports. Such standards ensure 
a fast exchange of the required information through inter-organisational networks as well as the integration of different ERP systems.

Last but not least, as far as the ICTs planning and management is concerned, an important part was the assessment and availability verification of the technologies that were previously selected to support the intermediary service processes. As mentioned in the previous section, suitable measures (i.e. further evaluation, acceptance and implementation, further development, or rejection) had to be derived for each of the selected technologies. Within the assessment phase, in order to cope with the different requirements and the need to identify the necessary measures for each partner, the use of a technology calendar proved to be really helpful to visualize critical temporal constraints (see Figure 7).

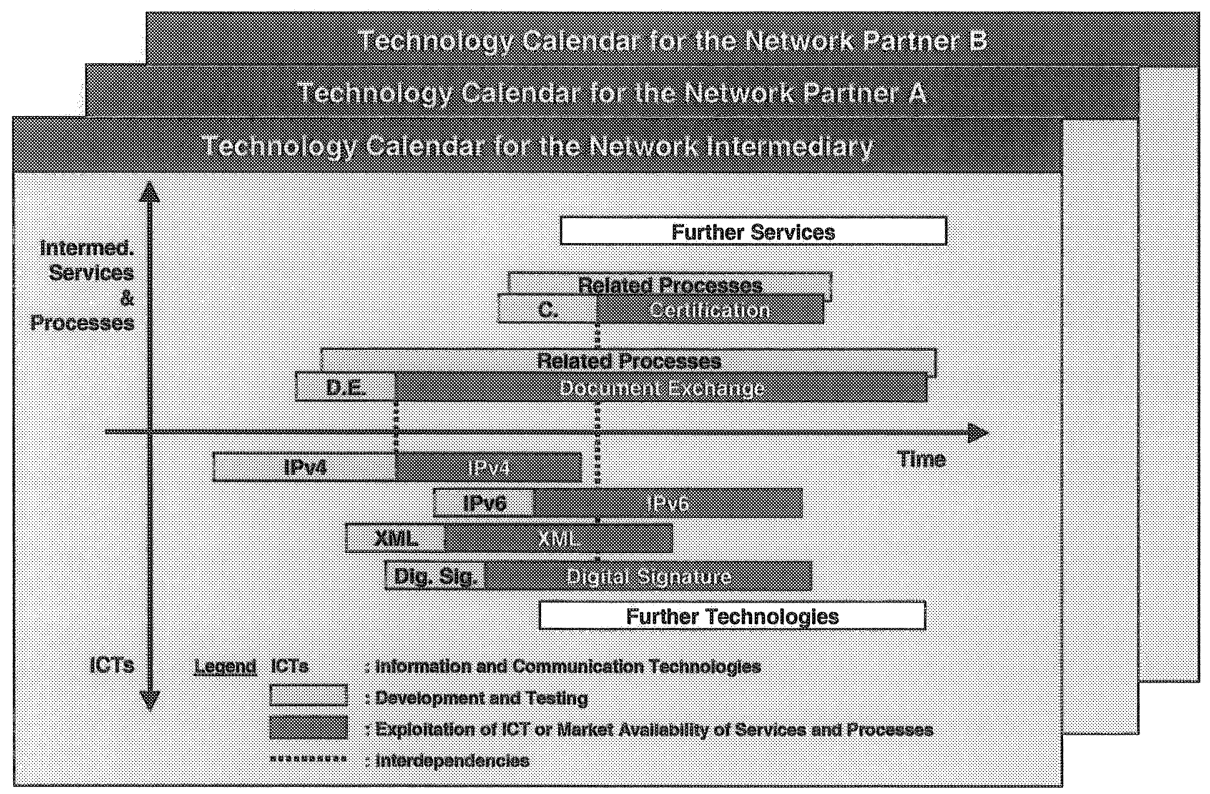

Figure 7-Integrated Planning of Intermediary Services and ICTS

\section{Financing model}

Because of clear privacy reasons, we are at the moment not allowed to distribute information about the financing model.

\section{CONCLUSIONS}

Until now, the development and adjustment of Business Models has been performed by companies mostly in a creative way. This was also confirmed by the "dot.com" crisis, in which weak or improvised Business Models lead both single enterprises and networks to unrecoverable bankrupts. A suitable approach to design Business Models for a networked economy is the House of Value Creation (HVC), a 
meta-method to design customer-oriented and sustainable Business Models. The meta-method was validated in a specific case, namely in the case of the information service intermediary of a collaboration network in the manufacturing industry. We are convinced that the HVC is also a promising approach for the development of Business Models in the case of inter-firm networks. Hence, in order to verify such a fact, we plan to test its validity also in other cases and for other branches, such as IT and logistics. Another interesting aspect is that the House of Value Creation can be also used to check the feasibility of existing Business Models as well as to further develop Business Models.

As far as the project of the case study is concerned, the first step was the development of the prototypic BCI solution. Nowadays, a commercial business pilot is being deployed with the participation of all the 10 enterprises of the consortium; the objective is to gather precious information about the feasibility of the developed Business Model as well as about the acceptance of the BCI as an efficient means to exchange material test reports. The next phase will be a commercial rollout, initially in the German market and, if the sustainability will be confirmed, on European level.

To conclude, the trend towards a tightly inter-connected economy seems to be nowadays unquestionable. On the other side, the development process towards a dynamically networked economy has just recently started. We strongly believe that, in order to be successful within a networked economy, enterprises will thus have to undergo a deep transformation process in their organisational philosophy, in their structure, in the used methods as well as in their approach to interact with external organizations. We are convinced that, in order to face the challenges of such a dynamic and insecure business context, an appropriate business modelling approach as well as an integrated technology and innovation management can be really helpful to plan and hence deploy sustainable businesses.

\section{REFERENCES}

[1] Afuah, A, \& Tucci, C.L. Internet Business Models and Strategies: Text and Cases. New York: McGraw-Hill/Irwin, 2001.

[2] Bensaou, M. Interorganizational Cooperation - The Role of Information Technology: An Empirical Comparison of US and Japanese Supplier Relations. In: Information Systems Research, 8(1997)2, 107 - 124.

[3] Bergner, K., Deifel, B., Jacobi, C., Kellerer, W., Rausch, A., Sabbah, A., Schätz, B., Sihling, M., Vilbig, A., Vogel, S. The Future of Information Technology - an interdisciplinary, scenario-based approach. Report of Tech. Univ. München, Institut für Informatik, München, 2000.

[4] Bleck, S., Beyer, M., \& Laing, P. Methodeneinsatz bei der Erschließung des E-Business - Ergebnisse einer Studie. In: Industrie Management, (2001)1, 21 - 26.

[5] Bleck, S., \& Quadt, A. Planning and employment of information and communication technologies in the field of intermediary services. In: Proceedings of the 6th Int. Conference Work With Display Units (WWDU 2002), Berchtesgaden 2002, 500 - 502.

[6] Bullinger, H. J. (Edt.), Einführung in das Technologiemanagement, B.G. Teubner Verlag, Stuttgart 1994.

[7] Forzi, T., \& Luczak, H. E-Business: Status Quo and Perspectives. In: Proceedings of the $6^{\text {th }}$ International Scientific Conference on Work With Display Units (WWDU 2002), 
Berchtesgaden (D), Luczak, H./ Cakir, A.E./ Cakir, G. (Eds), May $22^{\text {nd }}-25^{\text {th }}, 2002,494$ $-496$.

[8] Forzi, T., \& Laing, P. Business Modelling for E-Collaboration Networks. In: Proceedings of the 2002 Information Resources Management Association International Conference (IRMA 2002), Seattle, WA (USA), May 19-22, 2002, pp. 961 - 963.

[9] Daft, R., \& Lengel, R. Information Richness: A New Approach to Managerial Behaviour and Organization Design. In: Research in Organizational Behaviour, 1984 (6), $191-233$.

[10] Davenport, T.H. Process Innovation: Redesigning Business Processes with Information Technology. Harvard Business School Press, Boston 1993.

[11] DIN (publisher) 10 204. Metallic products - Types of inspection documents (German version). Beuth Verlag, 1990.

[12] Fink A., Schlake O., \& Siebe A. Wie Sie mit Szenarien die Zukunft vorausdenken. In: Harvard Business Manager, 2000 (2), 34 - 47.

[13] Gebauer, J., \& Buxmann, P. Assessing the value of interorganizational systems to support business transactions. In: $32^{\text {nd }}$ Hawaii International Conference on Systems Sciences (HICSS-32), Maui, 1999.

[14] Hagel, III J., \& Singer, M. Unbundling the Corporation. In: Harvard Business Review, $1999,77(2), 133-141$.

[15] Hoffmann, J. Entwicklung eines QFD-gestuitzten Verfahrens zur Produktplanung undentwicklung für kleine und mittlere Unternehmen, Dissertation. Universität Stuttgart, 1996.

[16] Hoeck, H., \& Bleck, S. Electronic Markets for Services - Requirements and the Road to Success for the Electronic Trade of C-Services. In: E-Work and E-Commerce - Novel Solutions and practices for a global networked economy, Vol. 1, Stanford-Smith B. \& Chiozza Editors, Amsterdam, Berlin, Oxford: IOS Press, 2001, 458 - 464.

[17] Holland, C. P., Lockett, G. Strategic Choice and Inter-Organisational Information Systems. In: Proceedings of the 27th Hawaii International Conference on Systems Sciences (HICSS-27). IEEE Computer Society Press, Los Alamitos, 4(1994), 405 - 416.

[18] Kim C., \& Mauborgne R. Knowing a Winning Business Idea When You See One. In: Harvard Business Review, 2000, 78(5), 129 - 138.

[19] Klein, S. Interorganisationssysteme und Unternehmensnetzwerke-Wechselwirkungen zwischen organisatorischer und informationstechnischer Entwicklung. Habilitationsschrift Univ. St. Gallen 1995.

[20] Kornelius, L. Inter-organisational infrastructure for competitive advantage: strategic alignment in virtual corporations. Doctoral Thesis Tech. Univ. Eindhoven, Eindhoven 1999.

[21] Krcmar H. Informationsmanagement. $2^{\text {nd }}$ edition. Berlin, Heidelberg, New York: Springer-Verlag, 2000.

[22] Laing, P., \& Forzi, T. Management of shared information within Manufacturing Networks. In: Proceedings of the $18^{\text {th }}$ International Conference on CAD/DAM, Robotics and Factories of the Future (CARs\&FOF'2002), July 3rd -5th, 2002 (=2002a), Porto (P), $459-466$.

[23] Laing, P., \& Forzi, T. Challenges for Business Modelling in the New Communication Era. In: Proceedings of the 31st Annual Meeting of the Western Decision Sciences Institute (WDSI 2002), April 2nd -5th, 2002 (=2002b), Las Vegas, NV (USA), 434 . 436.

[24] Laing, P., \& Forzi, T. E-Business and Entrepreneurial Cooperation. In: Proceedings of the 1st International Conference on Electronic Business (ICEB 2001), Hong Kong, December 19-21, 2001, 7-9.

[25] Molina, A., Ponguta, S., Bremer, C.F., \& Eversheim, W. Framework for Global Virtual Business. Agility \& Global Competition, 2 (1998)3, 56 - 69. 
[26] Mooney, J.G. The Productivity and Business Value Impacts of Information Technology: Economic and Organizational Analyses. Dissertation Univ. of California Irvine, Irvine 1996.

[27] Parolini, C. The Value Net: A Tool for Competitive Strategy. New York: John Wiley \& Sons Lid., 2000.

[28] Pfeiffer T. Qualitätsmanagement: Strategien, Methoden, Techniken. München: Hanser Verlag, 1993.

[29] Picot, A., Reichwald, R., \&Wigand R.T. Die grenzenlose Unternehmung - Information, Organisation und Management, 4th edition. Wiesbaden: Gabler Verlag, 2001.

[30] Pietsch, T. Bewertung von Informations-und Kommunikationssystemen. Einvergleich betriebswirtschaftlicher Verfahren. Erich Schmidt Verlag, Berlin 1999.

[31] Porter, M.E. Strategy and the Internet. Harvard Business Review 2001, 79(3): 63 - 68.

[32] Rayport, J. F. The Truth about Internet Business Models, 1999. Retrieved on September $27^{\text {th }}, 2001$, from the Web-site: www.strategy-Business.com/briefs/99301/page1.html.

[33] Rentmeister, J., \& Klein. St. Geschäftsmodelle in der New Economy. In: Das Wirtschaftsstudium, 2001, 30(3), $354-361$.

[34] Ropohl, G. Eine Systemtheorie der Technik. Hanser Verlag, München, 1999.

[35] Rose, F. The economics, concept, and design of information intermediaries; a theoretic approach, Dissertation Univ. Frankfurt, Frankfurt 1998.

[36] Ruohonen, M. Information Technology Mediated Activities in Organizational ContextsA Case of Strategic Information Systems Planning. TUCS Technical Report No 3, Turku Centre for Computer Science, Turku 1996.

[37] Schoder, D. Die ökonomische Bedeutung von Intermediären im Electronic Commerce, Habilitation Univ. Freiburg, Freiburg 2000.

[38] Teubner, R. A. Organisations-und Informationssystemgestaltung: theoretische Grundlagen und integrierte Methoden, Dissertation Univ. Münster, Gabler Verlag, Wiesbaden 1999.

[39] Timmers, P. Electronic Commerce - Strategies and Models for Business-to-Business Trading. John Wiley \& Sons, Ltd, 2000.

[40] Warnecke, H.J., Melchior, K.W., \& Kring J. Handbuch Qualitätstechnik: Methoden und Geräte zur effizienten Qualitätssicherung. Landsberg/Lech: Verlag Moderne Industrie, 1995.

[41] Wirtz, B.W. Electronic Business. Dr. Th. Gabler Verlag, 2000. 